\title{
ESTUDIO E IDENTIFICACIÓN DE LAS ENCUADERNACIONES DE TIPO IMPERIO DEL SIGLO XIX DE LA REAL ACADEMIA DE LA HISTORIA
}

\author{
Juan Bautista Massó Valdés* \\ Biblioteca Pública Villa de Vallecas "Luis Martín Santos" (Madrid). \\ Antonio Carpallo Bautista** \\ Universidad Complutense de Madrid
}

\begin{abstract}
Resumen: A finales del siglo XVIII se produce en la encuadernación un cambio desde el punto de vista decorativo predominando las estructuras formadas por ruedas dentro del movimiento neoclásico, dando lugar a primeros del siglo XIX al estilo imperio, con variantes como el estilo cortina en España y el estilo Bozérian en Francia. El presente artículo estudia las encuadernaciones de estos estilos depositadas en la Biblioteca de la Real Academia de la Historia, identificando algunos de sus encuadernadores, estructuras y motivos decorativos.

Palabras clave: Real Academia de la Historia; encuadernación artística; estilo neoclásico; estilo imperio; estilo cortina; estilo Bozérian.
\end{abstract}

Title: STUDY AND IDENTIFICATION OF THE TYPICAL EMPIRE OF THE XIX CENTURY OF THE REAL ACADEMY OF HISTORY.

Abstract: At the end of The 18th century a change takes place in the binding from the decorative point of view predominating over the structures formed by finishing roll of neoclassic type, giving place at the beginning of the 19th century to the style empire, with variants as the style curtain in Spain and the style Bozérian in France. The present article studies the bindings of these styles deposited in the Library of the Royal Academy of the History, identifying some of his binders, structures and decorative motives.

Keywords: Royal Academy of the History; artistic binding; neoclassic style; empire style; curtain style; Bozérian style.

\section{INTRODUCCIÓN}

La Real Academia de la Historia contiene en su biblioteca un fondo de unos 400.000 volúmenes, entre ellos se encuentran un gran número de encuadernaciones artísticas, desde recubrimientos con elementos góticos y mudéjares hasta encuadernaciones del siglo XIX, realizadas por los artistas más relevantes de cada época. El artículo que presentamos, forma parte de un trabajo mucho más ambicioso donde realizamos el estudio, la descripción y la difusión de las encuadernaciones artísticas de comienzos del siglo XIX que se encuentran en la Biblioteca de la Real Academia de la Historia. Entre nuestros objetivos están la identificación de estas encuadernaciones, su digitalización, la catalogación, la creación de un catálogo de hierros de cada encuadernador y la puesta en valor y difusión de este grupo de encuadernaciones.

Si analizamos los trabajos realizados hasta la fecha en España, el último publicado (Carpallo Bautista, 2015) hace referencia a las encuadernaciones artísticas del siglo XIX de la Biblioteca Histórica del Ayuntamiento de Madrid. Anteriormente la investigadora Matilde López Serrano había realizado una serie de artículos (López Serrano, 1950, p. 115-131 y 1967 p. 22-31) sobre los encuadernadores de finales del siglo XVIII y primeros del XIX como Gabriel de Sancha (López Serrano, 1975), Gabriel Gómez (López Serrano, 1945a, p. 68-71 y 1945b, p. 51-72), Santiago Martín (López Serrano, 1943, p. 14-28) y Antonio Suárez (López Serrano, 1942, p. 7-14), junto a otro artículo sobre el encuadernador Pascual Carsí y Vidal (Blas Benito, 1998, p. 33-46). También encontramos en la bibliografía dos artículos sobre el estilo imperio (Culot, 2000) y sobre el estilo cortina (López Serrano, 1978, p. 22-43), pero hasta la fecha no se había realizado estudio alguno sobre las encuadernaciones de estos estilos decorativos de los ejemplares de la Real Academia de la Historia.

Para el estudio de estas encuadernaciones la metodología seguida en la investigación consistió, en un primer momento, en la realización de un inventario de todas las encuadernaciones artísticas de la Biblioteca de la Real Academia de la Historia. Posteriormente, se realizó una clasificación por diversos criterios como los estilos decorativos, los encuadernadores, el estado de conservación, entre otros. Se ha digitalizado cada encuadernación,

\footnotetext{
*juanbautista.masso.valdes@madrid.org

**acarpall@ucm.es
}

Recibido: 25-06-2016; $2^{\mathrm{a}}$ versión: 13-01-2017; aceptado: 10-02-2017.

MASSÓ VALDÉS, J.B. y CARPALLO BAUTISTA, A. Estudio e identificación de las encuadernaciones de tipo imperio del siglo XIX de la Real Academia de la Historia. Anales de Documentación, 2017, vol. 20, $\mathrm{n}^{\mathrm{o}} 1$. Disponible en: http://dx.doi.org/10.6018/analesdoc.20.1.262111. 
estudiando cada ejemplar, que al ser único necesitaba de un análisis exhaustivo para identificar los materiales utilizados, las técnicas de construcción, las estructuras y los motivos decorativos, así como, los utensilios empleados, el estado de conservación y la identificación y el estudio de las marcas de propiedad, ya fueran manuscritas, impresas o estampadas.

Este artículo forma parte de los trabajos realizados dentro de un proyecto de investigación financiado por el Ministerio de Ciencia e Innovación para el periodo 2012-2014 titulado "Estudio, identificación y catalogación automatizada de las encuadernaciones artísticas de la Biblioteca de la Real Academia de la Historia" (FFI201125324) ${ }^{1}$ y de la tesis doctoral defendida por Juan Bautista Massó Valdés en septiembre de 2015 en la Universidad Complutense de Madrid.

Este estudio forma parte de otros llevados a cabo, como en la Biblioteca Histórica del Ayuntamiento de Madrid, Catedral de Toledo, Universidad Complutense de Madrid, Palacio de Liria y Real Academia de Bellas Artes de San Fernando, donde se han estudiado también encuadernaciones del mismo periodo, ayudando a crear un corpus de hierros de encuadernadores, lo que va a ayudar a la identificación de encuadernaciones en otras bibliotecas.

\section{LAS ARTES DECORATIVAS}

El siglo XIX es un periodo donde se producen movimientos políticos y sociales, como la Guerra de la Independencia (1808-1812) en España, además se desarrolla el nacionalismo y la industrialización. Destaca Francia como país influyente en las artes, en la política y en la sociedad. En los inicios del siglo XIX se produce el auge de la burguesía como mecenas, encargando obras de temas y motivos del gusto burgués, con sus propios gustos artísticos, que se verán reflejados e influenciados en las producciones decorativas de la época, que se impondrán al resto de representaciones. Predomina lo sencillo y lo austero, la estabilidad y lo convencional, las influencias prerrafaelista y se representan interiores nada ostentosos y escenas familiares.

Otros acontecimientos históricos también sirvieron de influencia e inspiración para las artes decorativas. Un hecho importante sucedió durante el reinado de Carlos III, siendo rey de Nápoles (1734-1759), cuando se producen los descubrimientos arqueológicos de Pompeya y Herculano en el segundo cuarto del siglo XVIII. Estos yacimientos influyeron directamente en los motivos decorativos y en los interiores de las representaciones artísticas.

Podemos afirmar que el arte del siglo XIX es ecléctico porque no produce un estilo propio. Utilizaron y recurrieron a estilos anteriores, dando lugar a una mezcolanza de estilos de otras épocas, donde se desarrollaron tanteos y experiencias en los diferentes países. Uno de los estilos representados es el neoclasicismo, nombre dado a los movimientos occidentales en las artes decorativas, que se inspiran en el arte «clásico» y la cultura de la antigua Grecia y Roma. Es un arte lleno de normas, que huye del movimiento y del color. El principal movimiento neoclásico coincidió con la Ilustración del siglo XVIII y continuó hasta principios del siglo XIX, llegando a competir con el Romanticismo. Surge como reacción al neoclasicismo siendo un arte de sentimiento, arrebatado y fogoso, lleno de fuerza y libertad. Los artistas reivindican la libre creación, sin someterse a normas. Técnicamente destaca la fuerza del color en poderosos contrastes, posturas arrebatadas y desequilibradas, gesticulación y claroscuros acusados.

A primeros del siglo XIX encontramos una variante del neoclasicismo en la arquitectura y las artes decorativas, el conocido como estilo imperio. Su nombre procede del momento histórico del Imperio Napoleónico (1804-1814), basado en motivos imperiales romanos y en las campañas militares y los descubrimientos de Napoleón en Egipto ${ }^{2}$. El modelo decorativo se corresponde con el «estilo Biedermeier» más burgués en los países de habla alemana, «estilo federal» en los Estados Unidos, el estilo «Regency» en Gran Bretaña y la «Napoleonstil» en Suecia. Una fase más temprana del estilo imperio fue el llamado «estilo de Adam» en Gran Bretaña y «Luis XVI» o «Louis XVI», en Francia.

\section{LAS ARTES DECORATIVAS EN LA ENCUADERNACIÓN}

Todos estos acontecimientos políticos, culturales y sociales que se produjeron durante finales del siglo XVIII y el primer cuarto del siglo XIX, supusieron una ruptura en la historia política de Europa ${ }^{3}$. Fueron fuente de inspiración e influyeron en las artes decorativas y en los artistas. Por lo tanto, el arte de la encuadernación y sus encuadernadores no iban a ser menos y se empaparon de estas vertientes y bebieron de las mismas fuentes que el resto de artistas. Aunque en las artes ligatorias no se aprecia ningún corte radical, sino que muchos de los motivos y modelos artísticos que servirán a la causa revolucionaria, se habían formulado con anterioridad a 1789 , como la «vuelta a lo antiguo», que convierte la antigüedad grecorromana en objeto de culto y se concreta dentro de las artes decorativas en una 
recuperación de sus ornamentaciones y adornos, aunque dentro de la corriente de austeridad que impregnará todos los estilos.

El destino de estas encuadernaciones solía ser el ámbito palaciego o regalos entre las clases sociales pudientes, con libros religiosos como misales, libros oficiales como ordenanzas o informes, estando muy cotizadas estas encuadernaciones si eran ejecutadas por Libreros-Encuadernadores de Cámara. Muchas de estas encuadernaciones vienen firmadas, algunas con los monogramas del encuadernador en el lomo, como el ejemplo de Ramón Cano (sig. 3/8958) (Figura 1); con etiquetas adheridas en la parte superior de la guarda anterior como la encuadernación de Antonio Suárez (sig. 14-11113) (Figura 5) con la ubicación del taller añadiendo la coletilla de «Encuadernador de Cámara de S.M.» y a veces se estampa en la parte inferior del lomo la leyenda «Cobo fecit» del encuadernador Tomás Cobo (sig. 13/3104) (Figura 6).

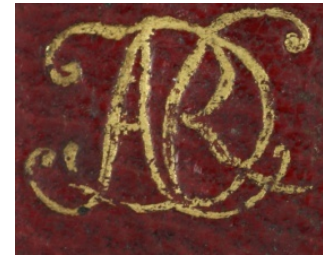

Figura 1. Monograma de Ramón Cano (sig. 3/9858).

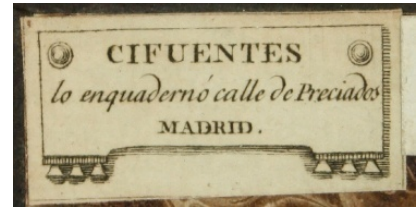

Figura 4. Etiqueta de Francisco Cifuentes (sig. 4/481).

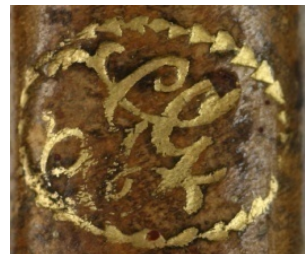

Figura 2. Monograma de Gabriel Gómez (sig. 3-289).

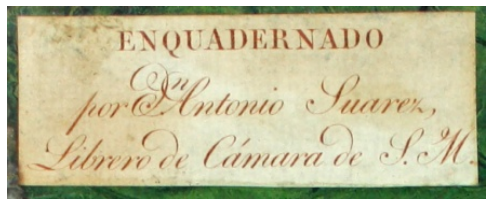

Figura 5. Etiqueta de Antonio Suárez (sig. 14/11113).

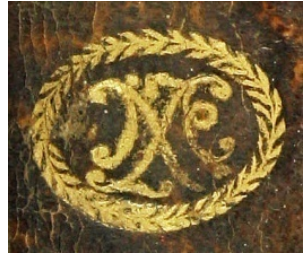

Figura 3. Monograma de Félix Ximénez (sig. 3/9473).

\section{SUARIY FECIT. \\ Firma de Antonio Suárez (sig.} 3141).

\section{COBO NECI}

Figura 6. Firma de Tomás Cobo (sig. 13/3104).

La Biblioteca de la Real Academia de la Historia cuenta con catorce ejemplares de encuadernaciones tipo imperio, de las cuales sólo tres pertenecen a alguna de las colecciones bibliográficas identificadas de la Biblioteca de la Real Academia de la Historia; dentro de la Colección San Román encontramos las signaturas 2/31 y la 1/1032, mientras que en el Fondo Ángel Ferrari tenemos la signatura 23/17423.

Se han identificado seis encuadernaciones firmadas por un maestro encuadernador, destacando los trabajos realizados por artistas franceses François Bozérian (1765-1818) (sig. 3/3337 y 3/3338), Lefebvre (1765-...) (sig. 2/31) y Antonio Menard $(\ldots+1914)$ (sig. 14/4450 y 11/8285); mientras que sólo hemos localizado e identificado una encuadernación que se le atribuye al artista español Enrique García Farach (sig. 14/4921).

\section{MARCAS DE PROPIEDAD Y CARACTERÍSTICAS CONSTRUCTIVAS Y DE MATERIALIDAD DE LAS ENCUADERNACIONES}

Analizando las procedencias y marcas de propiedad de estas encuadernaciones, normalmente los libros que ingresaban en la biblioteca llevan estampado el sello de «Biblioteca de la Real Academia de la Historia». Si alguno de los libros de nuevo ingreso pertenecía a la biblioteca particular de algún académico o persona ilustre que donaba su biblioteca a la institución, es habitual que encontremos alguna marca o vestigio de su propietario. Nos referimos a los libros de la Biblioteca del Marqués de San Román con alguno de los distintivos personales de Eduardo Fernández San Román, o los libros que componen el Fondo Ángel Ferrari pertenecientes al historiador medieval Ángel Ferrari Núñez y a su suegro, Ignacio Herrero de Collantes, marqués de Aledo ${ }^{4}$.

De las catorce encuadernaciones tipo imperio que custodia la RAH, ocho ejemplares contienen diferentes procedencias, desde notas manuscritas (sig. 14/4921 con la anotación manuscrita y firma de D. Vicente Castañeda y Alcover (1884-1958) y la sig. 14/4450 con una dedicatoria autógrafa de D. José Benavides), etiquetas de papel (sig. 1/1032 con el ex-libris del Depósito de la Guerra y la Biblioteca del Estado Mayor), sellos estampados (sig. 11/8285 con el sello de D. Juan Pérez de Guzmán (1841-1928), Secretario Perpetuo de la Real Academia de la Historia), exlibris heráldicos (sig. 3/7415 con las armas de Cuthbert Rippon, 1520-1591) y también motivos heráldicos en la parte 
central de sus tapas, como la signatura 14/4450 con los atributos papales de León XIII (1878-1903), la signatura 5/1403 con el Escudo Grande anterior a Carlos III con Toisón y Cruz del Espíritu Santo, bajo el reinado de Carlos IV (1748-1819) y la signatura 1/1032 con el escudo heráldico imperial de Napoleón I Bonaparte (1769-1821), rey de Francia, Legión de honor.

En cuanto a los materiales utilizados en la construcción en las siete encuadernaciones seleccionadas, las tapas de todas las encuadernaciones son de cartón, recubiertas de piel, al igual que el lomo, -algunas de marroquín (sig. 5/1403, 3/3337, 3/3338, 2/31), y otras de pieles jaspeadas o veteadas (sig. 23/17423, 13/3104, 14/11113)-, las guardas son de papel de diferentes colores -rosado (sig. 1/1032), azul (sig. 2/31)-, los cortes están decorados con pan de oro (sig. 1/1032, 5/1403, 3/3337, 3/3338, 2/31, 13/3104, 14/11113) o salpicados de pintura (sig. 23/17423), también aparecen cintas de registro de tela (sig. 1/1032, 3/3337, 3/3338, 2/31), el tejuelo de piel (sig. 23/17423), el núcleo de las cabezadas es una tira de cordel de fibra vegetal (sig. 1/1032, 5/1403, 23/17423, 3/3337, 3/3338, 2/31, 14/11113) o de piel doblada (sig. 3/3337, 3/3338, 13/3104) y los nervios en todas las encuadernaciones son de cordel de fibra vegetal.

Respecto a la estructura constructiva las tapas están encartonadas mediante tres nervios sencillos (sig. 23/17423, 13/3104), cinco nervios (sig. 1/1032, 5/1403, 3/3337, 3/3338), seis nervios (sig. 2/31) y siete nervios (sig. 14/11113), con un cosido a punto seguido y a la greca, lomo liso y redondeado, las guardas están realizadas con la técnica del marmoleado, que consiste es traspasar la pintura al papel a través del contacto de un líquido mucilaginoso contenido en una cubeta (sig. 23/17423, 3/3337, 3/3338, 13/3104, 14/11113).

\section{EL ESTILO NEOCLÁSICO}

En las artes de la encuadernación el estilo neoclásico, durante el reinado de Luis XVI, comienza a darse en la segunda mitad del siglo XVIII, pero su plenitud y máximo esplendor la alcanzará a finales de este siglo y primera mitad del siguiente. Apreciamos como esa ornamentación exterior en este período decae visiblemente, haciéndose muchas veces monótona, anodina y fría.

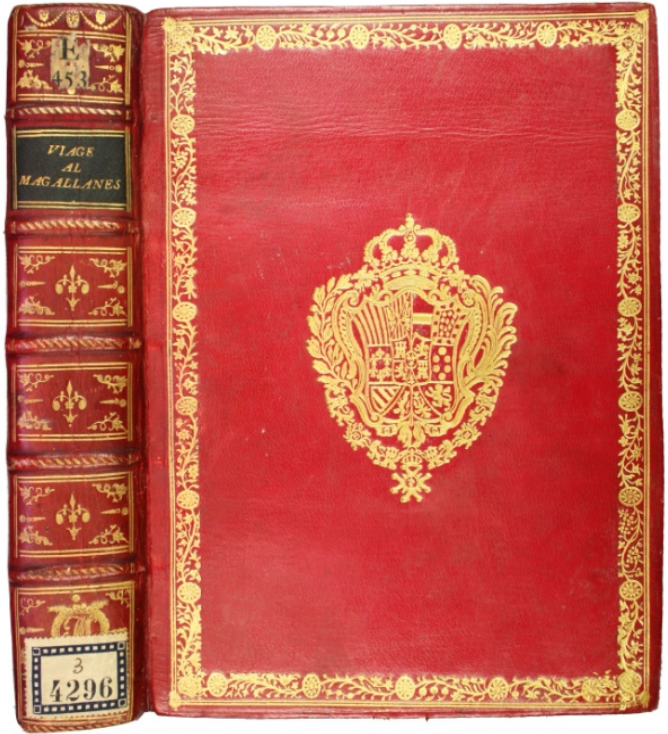

Figura 7. Encuadernación de Antonio Suárez (sig. 3/4296).

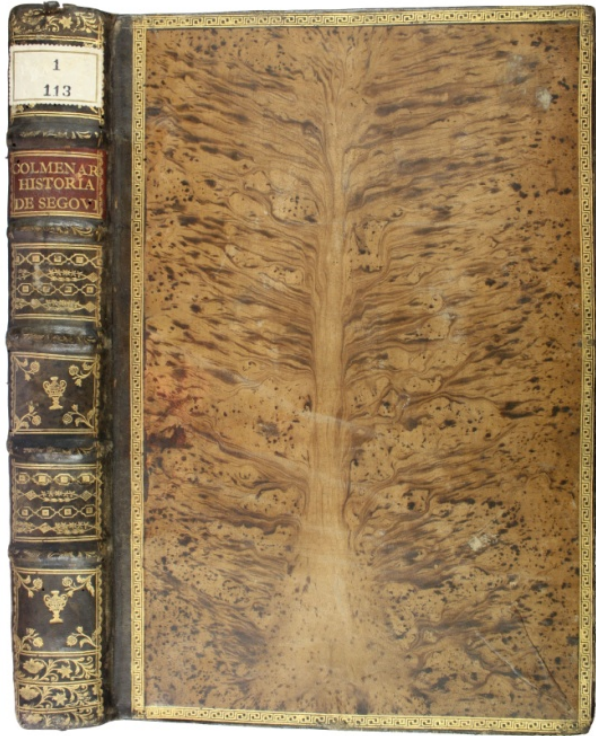

Figura 8. Encuadernación de Gabriel de Sancha (sig. 1/113). 


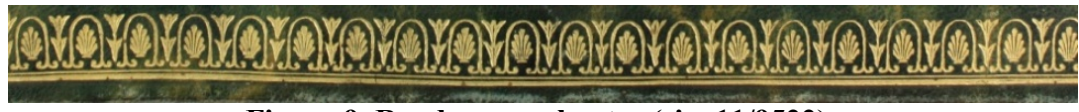

Figura 9. Rueda con palmetas (sig. 11/9522).

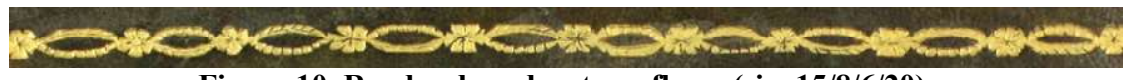

Figura 10. Ruedas de cadenetas y flores (sig. 15/8/6/20).

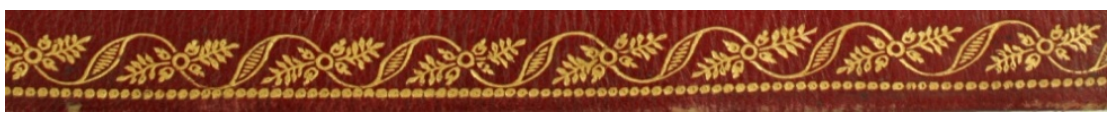

Figura 11. Rueda con postas y motivos florales (sig. 2/1186).

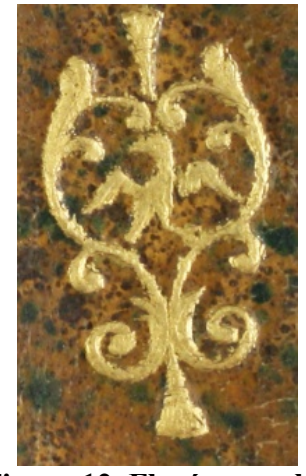

Figura 12. Florón con el pajarillo, muy utilizado por Félix Ximénez (sig. 14/156-157).

En cuanto a la decoración, se emplean hierros sueltos para la ornamentación del lomo (sig. 3/4296, Antonio Suárez) (Figura 7), donde se eliminan en ocasiones los nervios. Las tapas están decoradas con pequeñas orlas realizadas por medio de ruedas de hilos y motivos punteados, junto a otras ruedas con postas y motivos florales (sig. 2/1186) (Figura 11), cadenetas (sig. 15/8/6/20, Ramón Cano) (Figura 10) y palmetas (sig. 11/9522) (Figura 9). Se decoran los cantos y contracantos todo ello en dorado. Las ruedas empleadas eran las grecas (sig. 1/113, Gabriel de Sancha) (Figura 8) y meandros, junto a ruedas con motivos florales (sig. 4/2297) y motivos geométricos (sig. 1/1175). Entre los hierros sueltos destacan los elementos característicos de varios encuadernadores, que determinarán su autoría al no firmar sus encuadernaciones. En este punto estamos obligados a hacer referencia al hierro del pajarillo con las alas abiertas, utilizado por el encuadernador Félix Ximénez, ya utilizado en encuadernaciones francesas, y que caracteriza muchas de sus encuadernaciones (sig. 14/156) (Figura 12).

Los grandes maestros españoles del siglo XVIII siguen estando activos a principios del XIX, como por ejemplo Santiago Martín, Gabriel de Sancha, Gabriel Gómez, Pascual Carsí y Vidal, Antonio Suárez Jiménez, todos ellos Encuadernadores y Libreros de Cámara.

Al comenzar el siglo XIX los encuadernadores continuaron utilizando las mismas técnicas manuales que en períodos anteriores, con la adopción del lomo liso y el cosido a la greca. Los materiales de recubrimiento para las encuadernaciones de lujo eran el tafilete (predominando los colores rojo, azul y verde) siempre con adornos dorados y con el acompañamiento frecuente de guardas de moaré, la pasta valenciana de diferentes colores y la pasta española.

\section{EL ESTILO IMPERIO}

Uno de los primeros estilos decorativos del siglo XIX es el denominado estilo imperio, aunque a España no llega hasta la primera década de este último y se prolonga luego durante casi todo el reinado de Fernando VII.

Los encuadernadores españoles de finales del XVIII que continuaban trabajando a principios del XIX, como Santiago Martín ( $†$ 1828), Gabriel de Sancha $(† 1820)$, Gabriel Gómez († 1818), Pascual Carsí y Vidal († 1818) y Antonio Suárez († 1836), todos ellos Encuadernadores de Cámara, estuvieron entre los cultivadores de este estilo en nuestro país. Entre los encuadernadores franceses más relevantes que han ejecutado encuadernaciones siguiendo el esquema del estilo imperio, encontramos a Jean-Claude y François Bozerian, Antoine Lemonnier, Noël, Durand, Lefebvre, Pierre-Joseph Bisiaux, F. Bradel, Gendre, Joseph Thouvenin, Chilliat, Lecreux, Chapron, Debeauvais, JeanGeorges Purgold y René Simier.

Este estilo, de origen francés, se enmarca dentro del movimiento neoclásico y supone una evolución del mismo. Los motivos decorativos característicos son ruedas que tienden a ensancharse o a estamparse varias ruedas seguidas. Es un estilo decorativo a menudo pomposo, de formas pesadas y decoraciones superabundantes en el que predomina el naturalismo y los motivos florales.

La estructura decorativa de estas encuadernaciones se caracteriza por la solución de las tapas. En base de una orla confeccionada con ruedas de hilos y otras de motivos propiamente imperio, que se interrumpen en los ángulos por cuadrados, solucionan el problema del cruce de ruedas en las esquinas, consiguiendo una mayor riqueza decorativa ${ }^{5}$. Esos cuadrados contienen algún motivo decorativo ${ }^{6}$ o están ornamentados con pequeños mosaicos en pasta valenciana. 
Los elementos característicos que dan personalidad propia a este estilo, son los de tipo pompeyano ${ }^{7}$, combinados con motivos de tipo egipcio y otros florones como guirnaldas, rosas, palmetas y algunos elementos figurativos que empiezan a aparecer en relación con el contenido de la obra.

De los fondos de la Real Academia de la Historia hemos seleccionado tres ejemplares con una estructura de tipo imperio, caracterizados por incluir en sus esquinas un cuadrado ornamentado con un pequeño florón, impidiendo el solapamiento de las ruedas del encuadramiento exterior, y contener exlibris, inscripciones manuscritas y elementos heráldicos de los monarcas de la época, tanto de Francia como de España. Una de estas encuadernaciones contiene la obra titulada Relation de la Bataille de Marengo, cagnée le 25 prairialan 8, impresa en París por la Imprenta Imperial en 1806, sus dimensiones son 300 x 246 × 25 mm, su signatura 1/1032 y formaba parte de la Biblioteca Marqués de San Román.

Respecto a la estructura decorativa las tapas son simétricas y están decoradas por un encuadramiento exterior compuesto por una orla dorada de rameado de laurel dentro de un doble hilo puntillé; las esquinas se engalanan con una figura de marco cúbico con una estrella de cinco puntas radiada, todo en, dorado. La parte central presenta una ornamentación con un escudo heráldico imperial de Napoleón $\mathrm{I}^{8}$, Rey de Francia, Legión de honor. Los utensilios empleados han sido dos ruedas, un hierro suelto y una plancha. La técnica de decoración empleada ha sido el dorado (Figura 13).

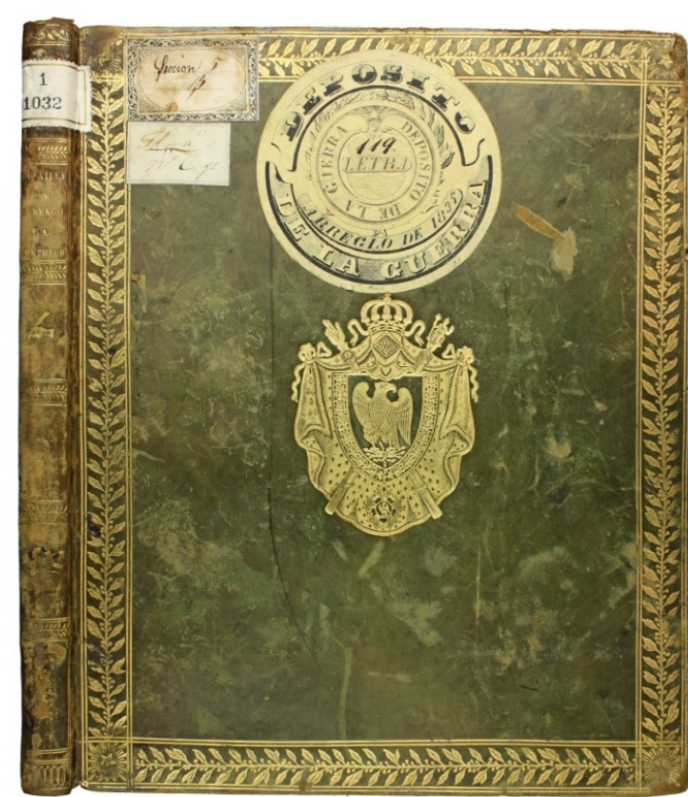

Figura 13. Tapa anterior y lomo.

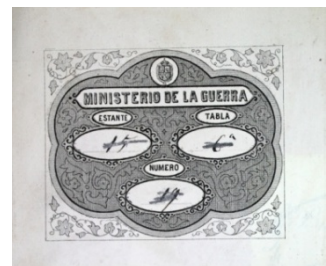

Figura 14. Exlibris del Ministerio de la Guerra.

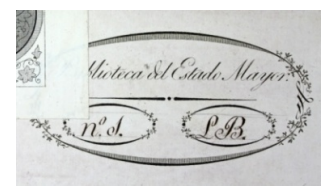

Figura 15. Exlibris de la Biblioteca del Estado Mayor.

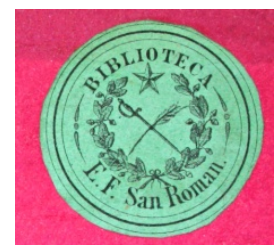

Figura 16. Exlibris de la Biblioteca de San Román.

El lomo está ornamentado con florones dorados de temática imperial, separados por una paleta de rameado vegetal entre dobles hilos también dorada. El tejuelo contiene la leyenda: «BATAILLE / DE / MARENGO / P.A. / BERTHIER». La cabeza y pie del lomo están decorados con una paleta de estilizados motivos vegetales y geométricos, los cantos con una rueda hilo anudado y los contracantos con una rueda de motivos florales geométricos, todo ello dorado. Las cabezadas del ejemplar se adornan con el alternado de hilos de seda de color rosado y los cortes se encuentran embellecidos con el dorado del pan de oro. La encuadernación se encuentra en buen estado, con rozaduras en las tapas y cantos del libro.

En la cubierta anterior aparece la etiqueta adherida del «DEPOSITO DE LA GUERRA ${ }^{9}$ (Figura 13); en la guarda anterior la etiqueta del «Ministerio de la Guerra ${ }^{10}$ » (Figura 14) y de la «Biblioteca del Estado Mayor» (Figura 15), junto con el ex libris de «Biblioteca - E.F. San Román» (Figura 16). En la portada se muestra estampado el sello de «R. Academia de la Historia-Biblioteca-San Román».

Otra de las encuadernaciones tipo imperio contiene la obra Oración fúnebre que en las exequias generales celebradas el día 23 de diciembre de 1805 expensas y devoción del Real Cuerpo de Marina del Departamento del 
Ferrol, por las ánimas de sus valerosos individuos ...dixo el doctor Don Manuel Fernández Varela, impresa en Madrid por la hija de Ibarra en 1806, con unas dimensiones de 362 x 246 x 17 mm y con signatura 5/1403.

Si estudiamos la estructura decorativa, encontramos que es simétrica en ambas tapas, y se basa en un encuadramiento exterior compuesto por una rueda dorada de estilizados motivos florales ondulados, flanqueada por una rueda de postas unidas y dentro de un doble hilo dorado; la orla interior está formada por una rueda dorada de estilizadas y pequeñas figuras geométricas, con una pequeña flor redondeada, rematando las esquinas. En la parte central se encuentra estampado el escudo real de España de Carlos IV ${ }^{11}$ (Figura 17). Los utensilios empleados han sido cuatro ruedas, dos hierros sueltos y una plancha. La técnica de decoración empleada ha sido el dorado.

Las guardas presentan una ornamentación con los efectos de brochazos de pintura azul sobre fondo blanco. El lomo está engalanado con un jarrón con basa, del que penden motivos vegetales a cada lado. Los nervios se muestran adornados con una paleta dorada de formas estrelladas y circulares, flanqueado por un doble hilo dorado y dentro de una paleta de postas unidas. Los cantos están decorados con una rueda de postas unidas, los contracantos con una rueda de hilo puntillé y la cofia también con una paleta dorada de hilo puntillé, todo ello dorado. Los cortes del ejemplar se embellecen con pan de oro. La encuadernación se encuentra en buen estado.

La tercera encuadernación tipo imperio que estudiamos contiene la obra titulada Noticia de las fundaciones cuyos patronatos corresponden a los señores decano del Consejo, formada de orden del Exmmo. Señor Conde de Campomanes, impresa en Madrid por Antonio de Sancha, en el mismo año de su muerte en 1790. Sus dimensiones son 184 x 121 x 20 mm, pertenece al Fondo Ángel Ferrari y su signatura es 23/17423.

En cuanto a la estructura ornamental observamos que las tapas son simétricas y están decoradas con un encuadramiento exterior compuesto por una greca dentro de un filete, con una flor redondeada en los espacios cuadrados que se forman en las esquinas, todo ello dorado. La parte central se encuentra adornada con un estampado liso. Los utensilios empleados han sido dos ruedas y un hierro suelto. La técnica decorativa utilizada ha sido el dorado (Figura 18).

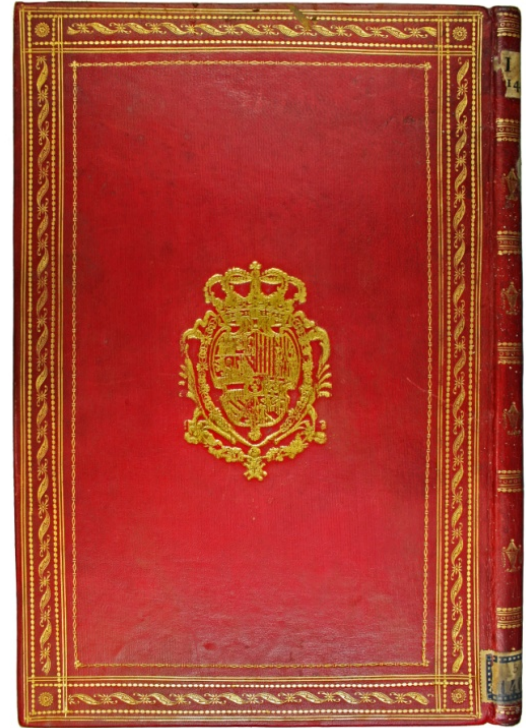

Figura 17. Encuadernación tipo imperio.

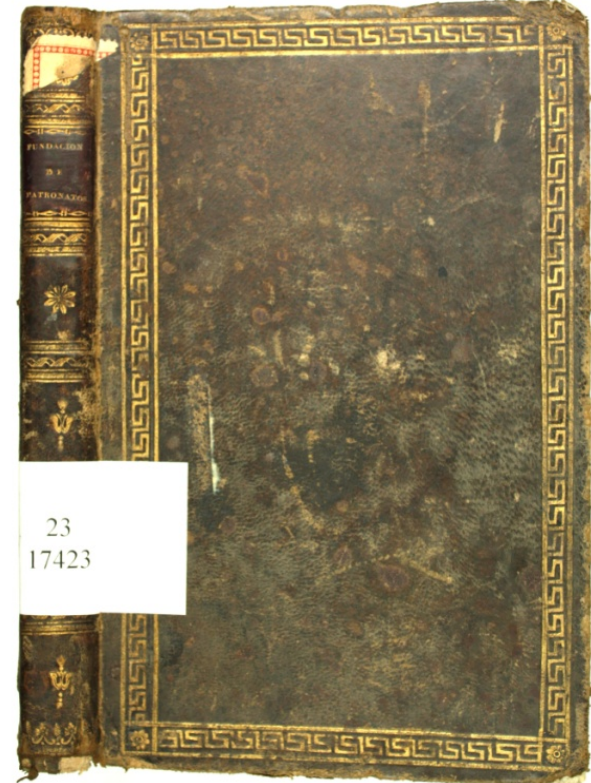

Figura 18. Tapa anterior y lomo. 


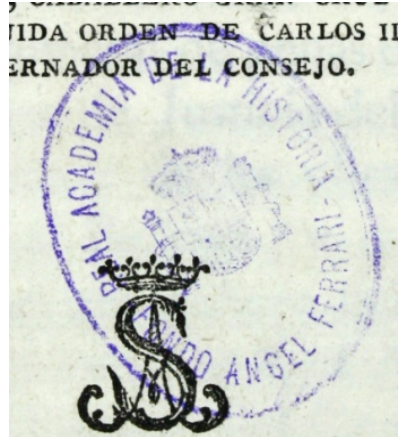

Figura 20. Sello del Fondo Ángel Ferrari de la RAH.

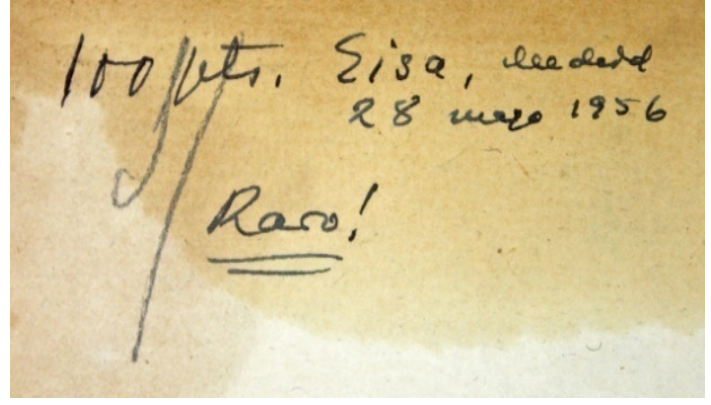

Figura 19. Nota mss. sobre el precio, tipo de libro y fecha de adquisición.

Las guardas están pintadas siguiendo el modelo denominado gotas tipo Shell y consiste simplemente en dejar la pintura tal como cae en el líquido; se han vertido sucesivamente gotas de colores y en el último se han añadido unas gotas de aceite de oliva; el primer color conforma el fondo del papel, mientras el último queda encima en forma de gotas redondeadas; la adición de unas gotas de aceite al color produce el efecto de un halo transparente alrededor de cada gota del color así preparado. A este tipo de diseño se le denomina Shell, también concha o caparazón.

El lomo presenta un florón vertical y un florón de forma circular, flanqueados por una paleta de triple hilo, todo ello dorado. Los nervios están engalanados con una paleta dorada de cinta en zig-zag. El tejuelo contiene la leyenda: «FUNDACION / DE / PATRONATOS». La cabeza y pie de imprenta están decorados con una paleta dorada de motivos florales y piñas, los cantos con una rueda gofrada de pequeños hilos en paralelo y los cortes con pequeñas gotas de color. La encuadernación se encuentra en buen estado, con rozaduras en las tapas y esquinas de los cantos del libro, donde se puede ver el cartón.

En la portada aparece estampado en el sello: «Real Academia de la Historia-Fondo Angel Ferrari» (Figura 20) y una nota manuscrita indicando el precio de 100 pts., y fecha de adquisición (28 de marzo de 1956), además de indicar que el libro es raro (Figura 19).

El estilo imperio desemboca en una variante denominada de tipo cortina, gracias a los encuadernadores José y Vicente Beneyto y Ríos, Pascual Carsí y Vidal y Antonio Suárez Jiménez, aunque también encontramos otra variante más de ámbito francés, conocida como Imperio-Bozérian.

\section{EL ESTILO BOZÉRIAN}

El estilo Imperio-Bozérian es una variante del propio tipo imperio y está representado por los hermanos encuadernadores François y Jean-Claude Bozérian y su sobrino Pierre-Lèger Lefebvre. Aunque no fueron de los artistas más destacados, crearon unas estructuras decorativas y ruedas reconocidas fácilmente en sus encuadernaciones, concediéndoles así su apellido. En este tipo de encuadernación se empleó mucho la rueda, utensilio más cercano y económico para la decoración de las tapas en época de crisis, notándose también la escasez de pieles de buena calidad y el uso de las medias encuadernaciones.

La firma de estos encuadernadores suele aparecer en la parte inferior del lomo. Rara vez se muestran obras sin firmar, lo que dificulta la identificación de quien de los dos hermanos fue el autor de la encuadernación debido a la similitud de sus estructuras, mosaicos, empleo de utillaje y uso de la piel marroquín de cuatro colores preferentemente, el azul oscuro, el rojo, el verde limón y el amarillo.

La decoración de las tapas se basa, en ocasiones, en ruedas que forman redes, ruedas de palmetas, hojas de roble, ramas de vid, liras, esfinges, tréboles de cuatro hojas, etc. Utilizan para sus decoraciones la ornamentación denominada "mil puntos" rellenando alguna superficie de pequeños puntos dorados.

Las ruedas empleadas por los hermanos Bozérian formaban encuadramientos con palmetas rectas con grandes o pequeños espirales, rosas, flores y vides entrecruzadas. Podemos confeccionar una pequeña clasificación de motivos empleados en este estilo: 
- En el primer grupo encontramos los hierros arquitectónicos neoclásicos y egipcios como perlas, rosas, follajes dispuestos en volutas, laureles, grecas, liras, urnas, ramas de roble, ramas de vides y ruedas de dos "C" adosadas y acodadas, estos tres últimos motivos son quizás lo más característicos de este estilo ornamental.

- El segundo grupo está compuesto por motivos cuya inspiración se basa en la época del Imperio Romano como héroes montados en carros, máscaras de Hermes, de Apolo, de Baco, urnas, esfinges, quimeras, cabezas de carneros, de caballos, de leones...

- En el tercer grupo aparecen motivos que se basan en la ornamentación de inicios del siglo XIX, entre ellos elementos procedentes de todas las ramas de las artes industriales y decorativas, motivos de inspiración arquitectónica, abanicos de ángulos, sobre todo realizados por Bozérian el Joven, y elementos que imitan motivos bordados.

- El cuarto grupo contiene hierros del Antiguo Régimen, especialmente los empleados por el encuadernador Nicolás-Denis Derôme.

- El quinto y último grupo se basa en el género inglés rico, con hilos que se entrecruzan formando tupidos enrejados.

Como es una variante del estilo imperio, el problema del solapamiento en las esquinas se continúa solucionando con pequeños cuadrados o incluso alguna marca de propiedad.

Como indicábamos con anterioridad la escasez de pieles determinó el uso de las medias encuadernaciones, lo que supuso la concentración de la decoración en el lomo, predominando los lisos sin nervios o con falsos nervios, conocidos como lomos a la Bozérian, estando cuajados completamente con hierros sueltos y sembrados de puntos, excepto los entrenervios destinados a los títulos, autores y números de volúmenes y tomos. Las paletas utilizadas contienen óvalos y gruesos hilos que dividen el espacio del lomo en seis compartimentos iguales: uno de ellos destinado al título y subtítulo y los otros cinco con una decoración uniforme cuajada de pequeños hierros repartidos alrededor de un ombligo central circular del que partían varias ramas de vides con hojas, mientras que en la superficie restante se muestran elementos vegetales de relleno con pequeñas liras, palmetas y ramas de vides con hojas, todo ello dorado aunque también podía aparecer un pequeño mosaico, dejando el fondo para cuajarlo de pequeños puntos.

Los cortes generalmente se adornaban con pan de oro. Las cabezadas Bozérian eran de seda bicolor o tricolor y de ellas colgaba una cinta de seda a modo de marcador de páginas.

Jean-Claude Bozérian firmaba sistemáticamente las encuadernaciones que salían de su taller empleando las siguientes fórmulas:

- Utilizó muy poco una etiqueta manuscrita aparentemente de su puño y letra en cursiva: Bozérian reliur/quai les augustins $/ n^{\circ} 33$.

- La firma más común es la que aparecía en la zona inferior del lomo con pequeñas letras doradas de componedor:

- En los formatos medianos y pequeños aparecía abreviada: R. P. BOZÉRIAN.

- Se mostraba la leyenda completa en los formatos en cuarto y mayores, al menos cuando el grosor del volumen lo permitía: RELIÉ PAR BOZÉRIAN.

- A la firma abreviada de Bozérian seguía a veces la mención ET LEFEBVRE o REL P. LEFEBVRE, sobrino y sucesor de Bozérian.

Las guardas solían ser de tabis $^{12}$ y se reforzaban con papel para que tomaran cuerpo e impedir que se deshilacharan. En algunos ejemplares se utilizó un marroquín granuloso de origen inglés en tonalidades desde el rojo y azul marino hasta el verde oscuro y amarillo limón, sin olvidar el becerro leonado.

Los Bozérian realizaban sus propios papeles de guardas, tanto para el interior como para el exterior de las medias encuadernaciones.

Este estilo supuso, dentro del movimiento imperio, una mayor creatividad, y entre los años 1790 y 1815 , marcó el camino hacia el estilo romántico.

Jean-Claude Bozérian (1762-1840) conocido como Bozérian el Viejo, fue primero aprendiz en Lyon, y en 1795 se trasladó a Paris hasta su retiro en 1818 y muerte de su hermano François Bozérian, llamado el Joven. No sólo se dedicó a la encuadernación sino que también era librero y editor y además bibliófilo. Durante la época napoleónica, Jean-Claude trabajó para el emperador, para sus hermanos José y Luciano Bonaparte y para el librero AntoineAugustin Renouard. Jean-Claude hizo fortuna con su trabajo, algo nada común. Fue alcalde de Meslay hasta su muerte en 1840. Le sucede su sobrino político Lefebvre abriendo un taller en la rue Saint-Christophe de Paris, estando activo 
desde 1805 hasta 1835 , por lo cual nos podemos encontrar encuadernaciones firmadas por Jean-Claude y Lefebvre desde 1805 hasta 1818 .

Unos años después de la muerte de Jean-Claude, en julio de 1846, sale a la venta su biblioteca en la localidad de Meslay, con más de 1.200 volúmenes donde se encontraban ediciones raras y curiosas y encuadernaciones de todo tipo.

François Bozérian (1765-1818) llamado el Joven, hermano menor de Jean-Claude, se instaló en la capital parisina entre 1801 y 1802 . Tenía un taller en la rue de Tournon. La existencia de este artesano no está clara aunque sabemos que trabajó, entre otros, para Fouché, ministro de Napoleón, y Amoine-Augustin Renouard. Su producción es considerable, por lo que es habitual encontrarse con encuadernaciones firmadas por este encuadernador en la Biblioteca Imperial (más tarde Nacional) de Francia. Sus actividades le ponen en contacto con las personas relevantes del mundo bibliófilo y también se relaciona con uno de los encuadernadores más importantes franceses Joseph Thouvenin.

Entre las obras de la Real Academia encontramos dos volúmenes (sig. 3/3337 y 3/3338) realizados por los hermanos Bozérian y uno firmado por su sobrino Lefebvre (sig. 2/31) perteneciente, éste último, a la colección del marqués de San Román.

Entre las obras de la Real Academia encontramos dos volúmenes (sig. 3/3337 y 3/3338) realizados por los hermanos Bozérian y uno firmado por su sobrino Lefebvre (sig. 2/31) perteneciente, éste último, a la colección del marqués de San Román.

Los dos primeros volúmenes componen la obra titulada Monumens Antiques, inedits ou nouvelle ment expliqués ... realizada por A. L. Millin y publicada en París en la imprenta de Didot Jeune en el año 1802. La obra está localizada con las signaturas 3/3337 y 3/3338, y se encuentra en buen estado. Fue realizada por François Bozérian el Joven (1765-1818) y sus dimensiones son 272 × 214 x $50 \mathrm{~mm}$. Identificamos que pertenece a este encuadernador francés por la composición de hierros sueltos en forma de «ombligo» que presenta en los entrenervios.

Respecto a la estructura decorativa las tapas son simétricas y están embellecidas por un encuadramiento exterior compuesto por una orla de motivos florales, dentro de un doble filete de diferente grosor; mientras que las esquinas están rematadas con un marco de doble hilo con una flor redondeada de cinco pétalos; la orla interior está compuesta por un doble hilo con hierros curvos que se entrelazan en el centro y en sus esquinas con un hierro de lazo, además podemos observar un pequeño florón en forma de hoja. Los utensilios empleados han sido tres ruedas y cinco hierros sueltos y la técnica decorativa ha sido el dorado (Figura 22).

Las guardas están pintadas siguiendo el modelo denominado gotas y consiste simplemente, en dejar la pintura tal y como cae en el líquido; los primeros colores forman un veteado por la fuerza de la trementina añadida al último color que queda encima en forma de gotas redondeadas divididas en múltiples celdillas en su interior. Este diseño recibe el nombre de Imperio o Stormont.

El lomo está ornamentado con una composición decorativa floral, formada por diferentes tipos de flores y hojas, dispuesta en torno a una flor redondeada central sobre un fondo de estilizado punteado dorado (Figura 24). Los nervios están decorados con una paleta de doble hilo dorado. El tejuelo contiene la leyenda: «MILLIN / MONUMENS / ANTIQUES»; «TOME I.» y «TOME II.» (Figura 21). El pie de imprenta presenta una decoración con una paleta de estilizados motivos geométricos. Los cantos están decorados con una rueda dorada en zig-zag. Los contracantos se engalanan con una rueda de motivos estrellados y redondeados y la cofia con una paleta de hilos en paralelo, todo ello dorado. Las cabezadas están adornadas con el alternado de hilos de seda de color rojo, blanco y beis (Figura 23). Los cortes se encuentran ornamentados con pan de oro. 


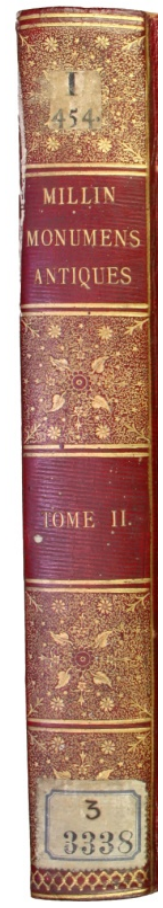

Figura 21.

Lomo.

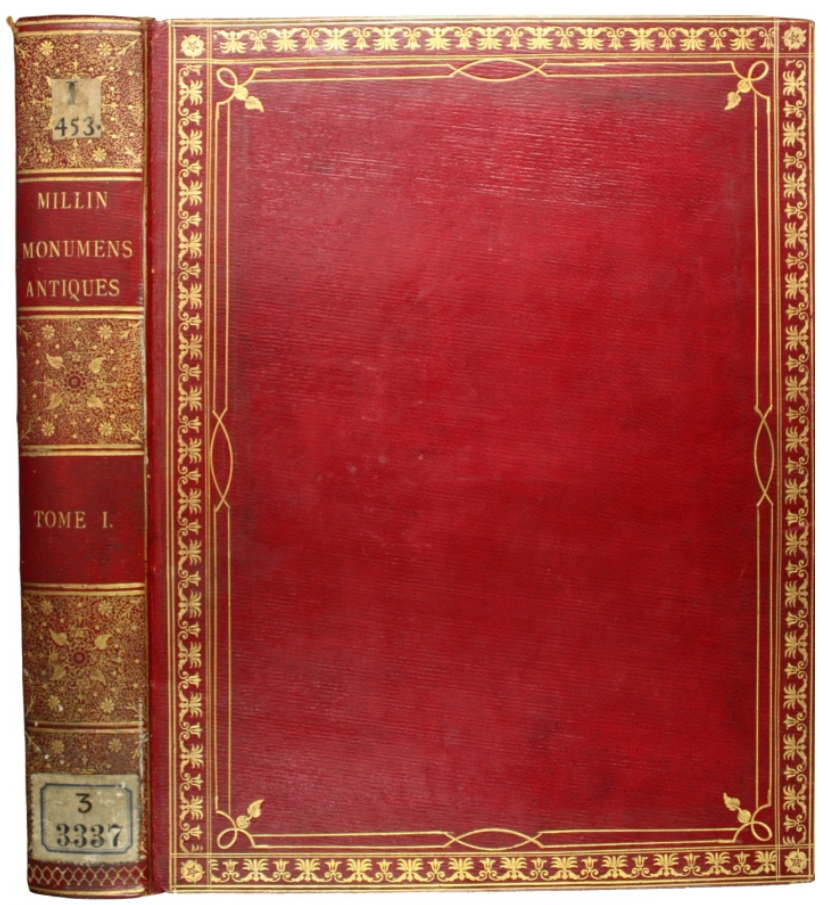

Figura 22. Lomo y tapa anterior.

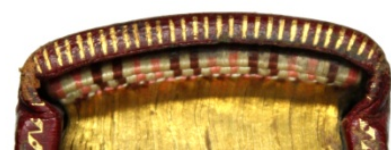

Figura 23. Cabezada y cofia superior.

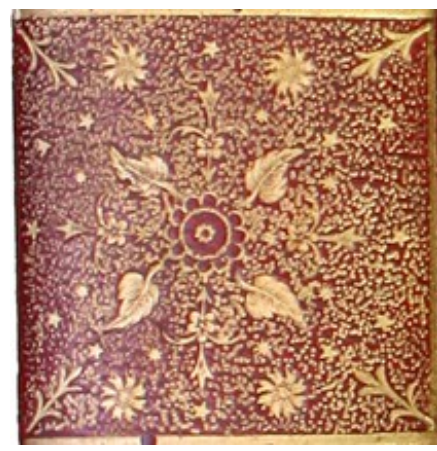

Figura 24. Detalle del entrenervio.

El tercer ejemplar de este grupo contiene el título Campagnes de Napoleon Premier: Tableux historiques des Campagnes d'Italie, depues l'anjus qu'a la Bataille de Marengo ...; et les estampes sont gravées d'apres les dessins originaux de Carle Vernet, impreso en París en la imprenta "De l'Imprimerie de L. E. Herhan" en el año 1806. Está ubicada con la signatura 2/31, aunque el ejemplar se encuentra en buen estado, la encuadernación muestra rozaduras en las tapas y esquinas de los cantos del libro, donde se puede ver el cartón. Pertenece a la colección del marqués de San Román, está firmada por el artista francés Lefebvre (1765-...) y sus dimensiones son 586 x 440 x 39 mm. En la portada aparece el sello de la «Real Academia de la Historia-Biblioteca-San Román» y el ex-libris de la «Biblioteca E.F. San Román».

Un aspecto a estudiar es la estructura y decoración de las diferentes partes de la encuadernación. Las tapas son simétricas y contienen un encuadramiento exterior compuesto por una rueda de eses inclinadas en la parte interior y una rueda de círculos y estrellas en la parte exterior, flanqueadas por un doble hilo cordado, junto a rueda de roleos vegetales en el centro. Los cuadrados que se producen en las esquinas están decorados con un florón de temática imperial dentro de un doble hilo cordado. Los utensilios empleados han sido cuatro ruedas y un florón. La técnica de decoración empleada ha sido el dorado (Figura 26). Las guardas se han realizado con papel mate de color azul.

El lomo está ornamentado con hierros de temática imperial, como las estrellas de cinco puntas, el águila imperial y los estandartes y cañones, flanqueados por un doble hilo dorado (Figura 25) y una paleta de estilizados motivos vegetales y circulillos (Figura 28). El tejuelo contiene la leyenda: «CAMPAGNES / DE / NAPOLEON / LE GRAND». La cabeza y pie de imprenta presentan una decoración con una paleta de campo de flores de tres pétalos. En este último lugar, se encuentra estampada la firma del encuadernador: «REL. P. LEFEBVRE» (Figura 29), flanqueado por un doble hilo dorado. Los cantos están embellecidos por un hilo con una especie de nudos, los contracantos con una rueda de estilizados pámpanos y racimos, unidos por arquillos, y la cofia por una paleta de pares de hilos, todo ello dorado. Las cabezadas presentan un alternado de hilos de seda de color rojo y blanco (Figura 27) y los cortes del ejemplar se decoran con pan de oro. 


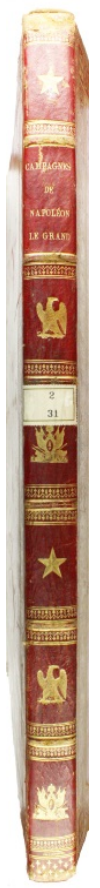

Figura 25 . Lomo.

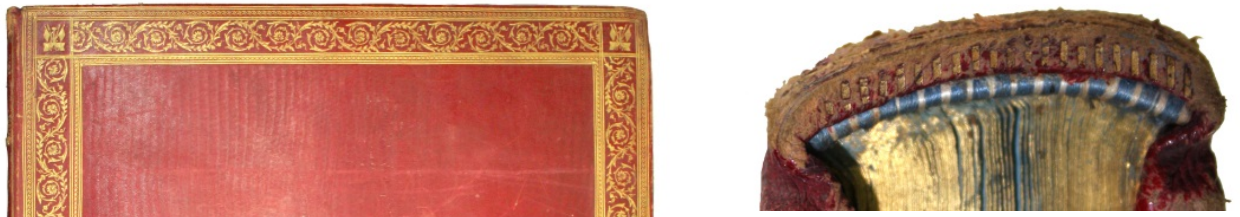

Figura 27. Cabezada y cofia inferior.

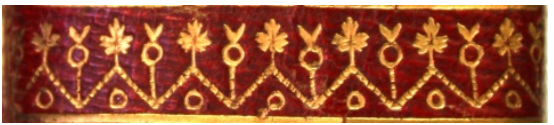

Figura 28. Paleta.

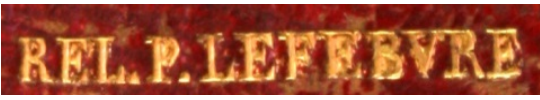

Figura 29. Firma del encuadernador.

\section{EL ESTILO CORTINA}

En España el estilo cortina se manifiesta con todas sus características ornamentales después de la Guerra de la Independencia; la mayor parte de este tipo de encuadernaciones se produjeron bajo el reinado de Fernando VII (18141833), a las que también se las conoce como encuadernaciones fernandinas, conservándose un gran número de ellas en la Real Biblioteca de Madrid, aunque también encontramos ejemplares en la colección Rico y Sinobas de la Biblioteca Nacional y en otras bibliotecas, como la Fundación Lázaro Galdiano, Real Academia de la Historia, Palacio de Liria o en la Biblioteca Histórica de Madrid.

El estilo cortina es una variante específica española que la podemos enmarcar dentro de las encuadernaciones de tipo imperio, caracterizándose por los diseños que presentan imitando los pliegues de las cortinas, y que aparecen en diferentes lugares del libro, viéndose una gran variedad en la disposición de estos pliegues. Para dar más vistosidad a estas ornamentaciones se combinan con el uso de pieles valencianas o jaspeadas dando lugar a espectaculares mosaicos con pieles de diferentes tonalidades, produciendo efectos de luces y sombras propios de las cortinas plegadas, suponiendo una evolución y una novedad en la ornamentación de las encuadernaciones. Las pastas valencianas fueron creadas por el encuadernador valenciano José Beneyto y Ríos entre 1770 y 1780 . Fueron muy utilizadas entre el reinado de Carlos IV (1789-1808) y Fernando VII (1814-1833). El sistema del jaspeado consiste en sumergir las pieles en tintes, una vez arrugadas para conseguir diferentes tonalidades, consiguiendo pieles jaspeadas de colores azules, amarillos, rojos y verdes, imitando los tonos de los papeles empleados en las guardas. Las cortinas aparecen acompañadas de las mismas ruedas y pequeños hierros sueltos, como cruces, flores, estrellas, utilizadas en las encuadernaciones neoclásicas y de tipo imperio. Los pliegues de este tipo de encuadernaciones los podemos encontrar con diferentes disposiciones: una semicortina ocupando gran parte de la tapa, siendo el motivo ornamental principal; una cortina entera ocupando la parte central de la tapa; pequeñas cortinas en los ángulos de las tapas imitando las ornamentaciones de las encuadernaciones abanicos del siglo XVII; fragmentos de pliegues dispuestos en las bandas verticales y horizontales de acordeón; dos semicortinas decorando el centro de la tapa y que forman un gran rombo; y pliegues de cortinas dispuestos en bandas diagonales, de todas formas estas estructuras las podemos encontrar con numerosas variantes en sus disposiciones. La autoría de estos modelos ornamentales en las encuadernaciones ha recaído en el encuadernador madrileño Antonio Suárez Jiménez, que realizó estos primeros diseños sobre 1812 en su taller ubicado en Valencia. 
El motivo de las cortinas no procede de Francia sino de Inglaterra, concretamente de los diseños de varios arquitectos que decoraron sus edificios con elementos muy parecidos, como los pliegues de acordeón o radiales, a los de las cortinas que utilizaron los encuadernadores españoles. Es posible que Antonio Suárez Jiménez, el creador de este estilo decorativo, llegara a conocer las obras de estos arquitectos.

También cultivaron estos modelos otros encuadernadores de renombre de primeros del XIX, como Santiago Martín, Pedro Pastor, Francisco Cifuentes, Tomás Cobo, Gabriel de Sancha y Miguel Ginesta, en Madrid; José y Vicente Beneyto y Ríos en Valencia; Antonio Tubella en Barcelona y Francisco Magallón en Zaragoza (Carpallo Bautista, 2015, p. 33-34). En la Biblioteca de la Real Academia de la Historia encontramos dos ejemplares tipo cortina: la primera, con sig. 13/3104, está firmada por Tomás Cobo en la parte inferior del lomo; mientras que la segunda, con sig. 14/11113, está realizada por Antonio Suárez según se indica en una etiqueta adherida en la guarda anterior, utilizándose la técnica del mosaico en las tapas para dar el efecto de luces y sombras de los pliegues de las cortinas en ambas encuadernaciones.

El primero lleva por título Descripción de las Alegorías pintadas en las bóvedas del Real Palacio de Madrid, por D. Francisco José Fabre impreso en Madrid en la imprenta de D. Eusebio Aguado, Impresor de Cámara de S.M., en el año 1829. Su signatura es $13 / 3104$ y la encuadernación está en buen estado, con ligeras rozaduras en los cantos. Sus dimensiones son 214 × 154 × $30 \mathrm{~mm}$. En la portada observamos el sello estampado de la «Real Academia de la Historia-Biblioteca».

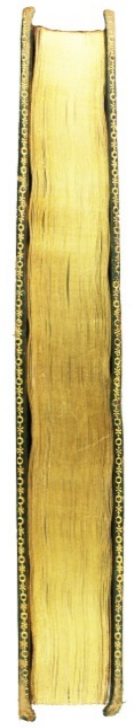

Figura 30. Corte delantero.

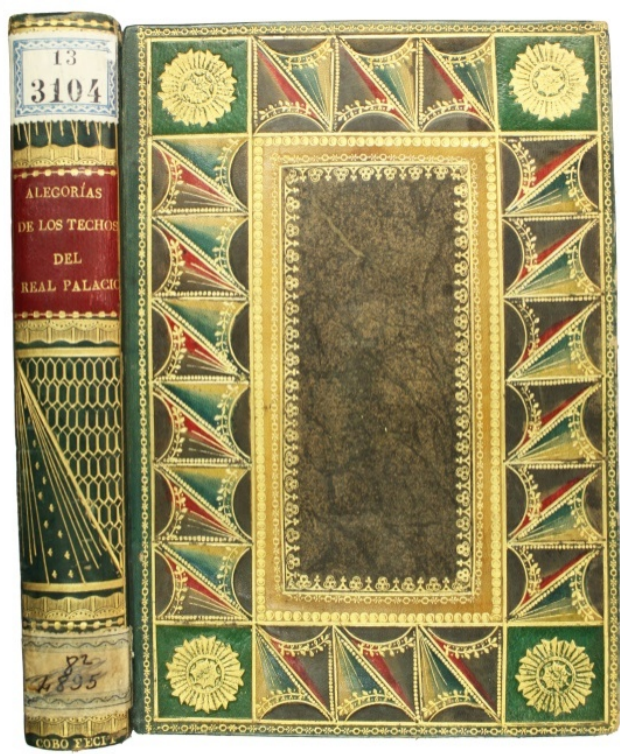

Figura 31. Tapa anterior y lomo.

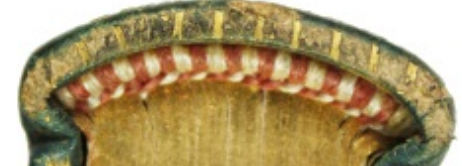

Figura 32. Cabezada superior y cofia.

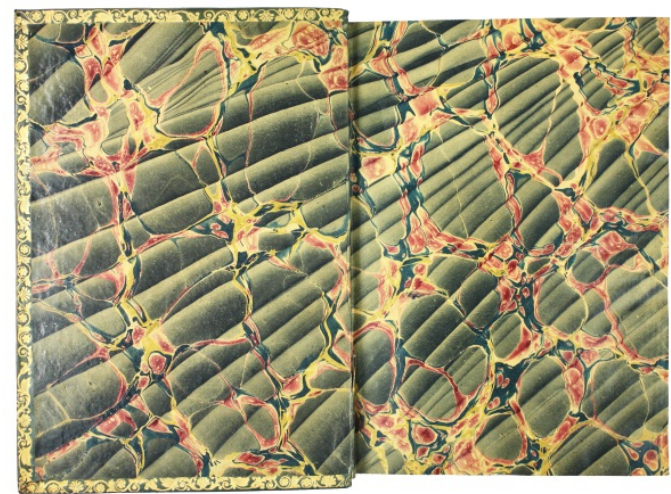

Figura 33. Tapa anterior con papel marmoteado.

Las tapas son simétricas y están ornamentadas por un encuadramiento exterior, formado por una rueda de pequeñas estrellas y circulillos, seguida de una orla con una composición de hierros sueltos con efectos de cortina. Las cuatro esquinas contienen un florón redondeado, junto a una orla de postas, en la parte interior. El rectángulo interior presenta una rueda de estrellas y circulillos, mientras que la última orla que enmarca la parte central, está compuesta por motivos geométricos sobre un hilo sencillo. El espacio central contiene un jaspeado de color marrón. Los utensilios empleados han sido cuatro ruedas, un florón y cuatro hierros sueltos y las técnicas de decoración utilizadas han sido el dorado y el mosaico (Figura 31). Las guardas se han realizado siguiendo el modelo denominado gotas, y consiste simplemente, en dejar la pintura tal y como cae en el líquido; posteriormente el papel se ha colocado de forma especial, con pequeños movimiento hacia delante y hacia atrás hasta cubrir todo el baño, produciéndose así la apariencia del denominado plegado español, es decir, una serie de líneas que confieren un cierto movimiento al diseño (Figura 33). El lomo aparece adornado con una composición de hierros sueltos produciendo efectos de cortina entre paletas de biseles. El tejuelo contiene la leyenda: «ALEGORIAS / DE LOS TECHOS / DEL / REAL PALACIO», entre una paleta de postas con hilo punteado. En el pie de imprenta aparece la firma del encuadernador Tomás Cobo: «COBO FECIT». Los cantos están decorados con una rueda de formas redondeadas y estrelladas, los contracantos con una rueda de formas vegetales y florales y la cofia con una paleta de hilos en paralelo, todo ello dorado (Figura 32). 
Las cabezadas presentan un alternado de hilos de seda de color rosado y blanco. Los cortes del ejemplar se adornan con pan de oro (Figura 30).

Y el segundo de ellos, recoge la Ordenanza de la Junta de Gobierno y de la Suprema de Apelaciones de la Real Casa, y Patrimonio, impreso en Madrid por la Imprenta Real en el año 1817. Su signatura es 14/11113 y su encuadernación se encuentra en buen estado. Es una obra que está dentro de la colección de Adolfo Herrera, como lo atestigua su ex-libris «Biblioteca Adolfo Herrera», con forma de etiqueta de papel, adherida a la guarda anterior.

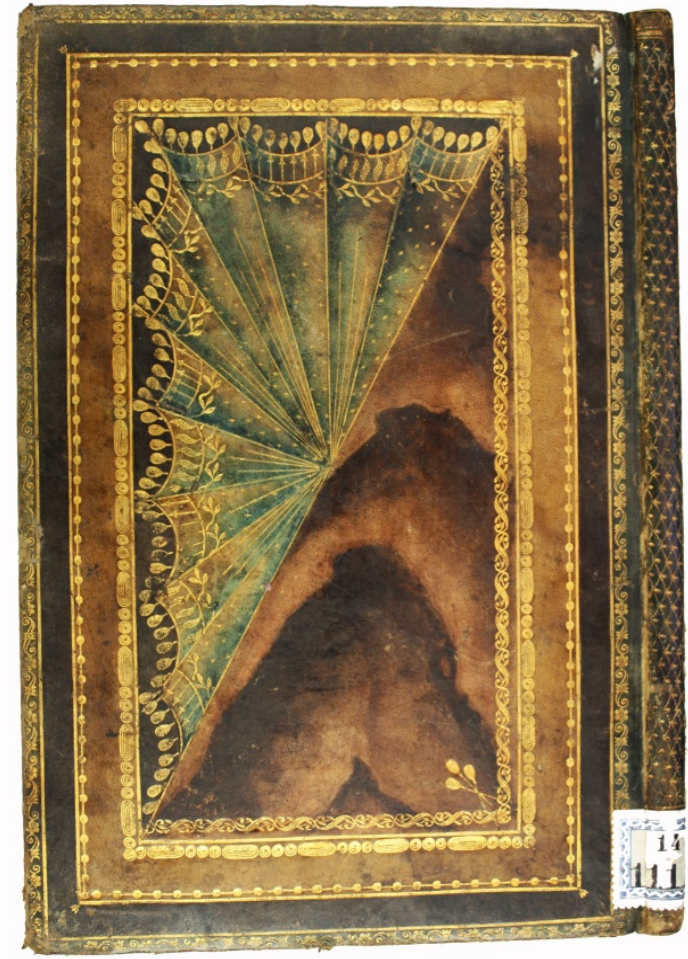

Figura 34. Tapa posterior.

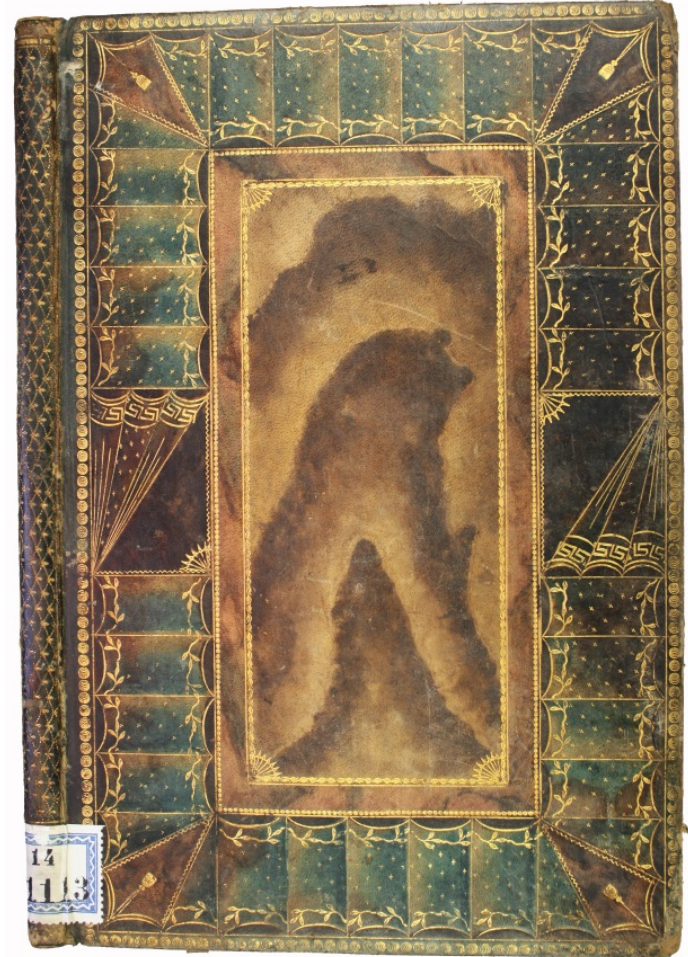

Figura 35. Tapa anterior.

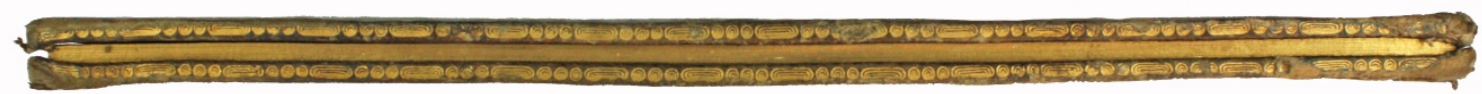

Figura 36. Corte delantero.

La estructura decorativa de las tapas no es simétrica: la tapa anterior aparece ornamentada con un encuadramiento exterior formado por una orla de postas, seguida de una composición de hierros sueltos con efecto de los plegados de las cortinas, que se encuentran divididos por hilos en paralelo produciendo compartimentos, adornados con pequeñas estrellitas, hierros curvos y rameados vegetales; le sigue una rueda de postas y otra interior de motivos vegetales, con un ramo de flechas en sus cuatro ángulos; la parte central está decorada con un estampado liso de piel veteada. Los utensilios empleados para la decoración de esta tapa, han sido cinco ruedas y numerosos hierros sueltos (Figura 34).

La tapa posterior está decorada con un encuadramiento exterior compuesto por una rueda de formas onduladas y pequeñas florecillas sobre un hilo dorado, seguida de una rueda de postas unidas por un fino hilo, y a continuación aparece una rueda de tres postas y un óvalo; la parte central está dividida oblicuamente, la mitad inferior está adornada con una rueda de estilizados motivos entrelazados, con un florón en su ángulo; mientras que la mitad superior, presenta una ornamentación con grandes efectos de plegados de cortina, a base del jaspeado de las pieles junto a hierros sueltos. Los utensilios empleados para la decoración de esta tapa, han sido cinco ruedas y diferentes hierros sueltos y las técnicas utilizadas en ambas tapas han sido el mosaico y el dorado (Figura 35).

La decoración de las guardas sigue el modelo denominado gotas y consiste simplemente, en dejar la pintura tal y como cae en el líquido; posteriormente el papel se ha colocado de forma especial, con pequeños movimiento hacia delante y hacia atrás hasta cubrir todo el baño, produciéndose así la apariencia del denominado plegado español, es decir, una serie de líneas que confieren un cierto movimiento al diseño. El lomo presenta una ornamentación mediante una paleta de motivos punteados con forma de pequeños arcos continuos, en los cantos se muestra una rueda de postas 
irregulares, y los contracantos contienen una rueda de hilo puntillé. Las cabezadas se han realizado mediante el recubrimiento de papel. Los cortes del ejemplar se adornan con pan de oro (Figura 36).

\section{CONCLUSIONES}

Para finalizar nuestro estudio, y después del análisis pormenorizado de algunas de las encuadernaciones neoclásicas y tipo imperio de primeros del siglo XIX, extraemos varias conclusiones.

La primera de ellas se refiere a que la mayoría de estas encuadernaciones artísticas, que custodia la Real Academia de la Historia, llegaron por medio de donaciones de sus antiguos académicos, que tuvieron el gusto de que sus obras fueran encuadernadas por los mejores artistas de la época, o incluso, encuadernaciones francesas adquiridas con posterioridad, es decir que los antiguos poseedores eran auténticos bibliófilos, que gustaban de obras, muchas de ellas francesas, y con decoraciones propias de la época.

La segunda conclusión que podemos extraer del estudio es que las estructuras decorativas de las encuadernaciones españolas tienen una gran influencia de las estructuras seguidas por los encuadernadores franceses, como se observa en la utilización de florones, ruedas y paletas, similares a las empleadas por varios de los grandes encuadernadores reales franceses de la época. Esta moda ha sido continuada por encuadernadores del siglo XX como Emilio Brugalla. El hecho de que los encuadernadores españoles estuvieran influenciados por la moda estilística francesa lo podemos observar en la utilización de los mismos motivos decorativos que aparecen en catálogos de bronces franceses y que fueron adquiridos por los encuadernadores españoles en sus frecuentes visitas a París, que realizaban tanto para la compra de nuevo utillaje como para mejorar su formación.

Sin embargo, en las encuadernaciones españolas predomina el empleo de la pasta valenciana y pasta española, mientras que en las encuadernaciones francesas se decantan por el marroquín y el tafilete de colores, lo que indica que en esta ocasión los encuadernadores españoles optaron por pieles con diseños propios, aunque utilizando un utillaje similar al de las encuadernaciones francesas. Esa diferencia en el empleo de las pieles jaspeadas hace que, las encuadernaciones realizadas por los artesanos españoles, tengan una característica diferente y enriquecedora que no tienen las francesas.

El estudio de los utillajes, la comparativa con otros estudios realizados y las firmas de los encuadernadores mediante etiquetas, monogramas o fórmulas en la parte inferior del lomo, nos han ayudado en la identificación de encuadernadores. La influencia francesa es evidente dado que París era el referente de la encuadernación en esa época.

\section{NOTAS}

1 Forman parte de este proyecto de investigación los investigadores Antonio Carpallo Bautista (IP), Adelina Clausó García, Esther Burgos Bordonau, José Luis Sánchez-Molero, Ana Belén Sánchez Prieto, Arsenio Sánchez Hernampérez y José María de Francisco Olmos, con la participación como miembros del equipo de trabajo de Juan Bautista Massó Valdés y Montserrat Calvo Rodríguez. También este estudio está dentro de las líneas de investigación del grupo Bibliopegia de la Facultad de Ciencias de la Documentación de la Universidad Complutense de Madrid sobre la Encuadernación y el Libro Antiguo (941369).

${ }^{2}$ Estos triunfos militares y hallazgos arqueológicos servirán de inspiración para los diferentes motivos decorativos, como fueron el descubrimiento de la piedra de Rosetta, motivos de palmetas, metopas, esfinges, motivos imperiales y motivos de influencia de la Roma Imperial. En definitiva, temas que tratan de dar esplendor al poder.

${ }^{3}$ La Revolución Francesa de 1789, seguida de la desaparición de las instituciones del Antiguo Régimen y sus principios organizativos (sociedad estamental, privilegios de la nobleza y el clero, origen divino de la soberanía, etc...).

4 En muchas de las encuadernaciones y libros ubicados dentro del Fondo de Ángel Ferrari, aparece el exlibris adherido a la guarda anterior en forma de etiqueta de papel color sepia, con las armas identificativas del marqués de Aledo, Ignacio Herrero de Collantes, suegro de Ángel Ferrari, que también era bibliófilo y académico de la RAH.

Ángel Ferrari contribuyó a la formación de la biblioteca del marqués, su suegro, de la que más tarde heredaría una parte. Como heredero de tal parte, quiso continuar su colección de historias locales. Cuando el tema podía ser considerado local compraba dos ejemplares: uno, para su biblioteca, y otro, para continuar con la colección de su suegro.

Por ese motivo aparece en la guarda de la tapa anterior de mucho de los libros del Fondo Ángel Ferrari, el exlibris con la armería del suegro. Sabemos que ese libro le perteneció porque ese distintivo heráldico refleja los apellidos de Ignacio Herrero de Collantes y porque, además, Ángel Ferrari Núñez nunca fue marqués consorte de Aledo, ya que el título lo heredó el único varón de Ignacio Herrero de Collantes y no la primogénita de éste (M. ${ }^{a}$ Teresa Herrero y Garralda) con la que se casó Ferrari. Por tanto, todas estas encuadernaciones debieron ser primeramente del suegro, y después, pasaron a manos del yerno a través de la herencia de parte de la biblioteca, quien finalmente la donaría a la Biblioteca de la RAH. Otro dato más que contribuye a reforzar esta hipótesis es la temática que tiene este libro, de viajes, la preferida por el marqués de Aledo para coleccionar.

${ }^{5}$ Parece que el primero en utilizar este recurso decorativo fue Pascual Carsí y Vidal.

${ }^{6}$ Corona real, mariposa, rombo relleno de una roseta, una composición floral, una pequeña cortina..

${ }^{7}$ Como cariátides, urnas, bailarinas, frisos de hojas de olivo, florones, estrellas, rayos, liras, cabezas de león, quimeras, volutas y trofeos de armas. 


\footnotetext{
${ }^{8}$ Napoleón I Bonaparte fue un general y gobernante francés (nació el 15 de agosto de 1769 en Córcega y murió el 5 de mayo de 1821 en la isla de Santa Elena) conocido por llegar a conquistar y controlar la mayor parte de Europa.

Tras una década de «éxitos militares», ascendió con un golpe de estado a la jefatura del estado francés como Primer Cónsul de la República (1799) y luego fue proclamado emperador de los franceses (1804) hasta su primera abdicación (1814), luego volvió a Francia durante los llamados Cien Días hasta ser derrotado finalmente por la Séptima Coalición en la Batalla de Waterloo (18 de junio de 1815, en Bélgica). Pocos días después volvía a abdicar, siendo exiliado a la isla británica de Santa Elena, donde murió.

La descripción del escudo corresponde a un escudo imperial napoleónico con blasón a campo pleno con el águila imperial de Napoleón I sobre haz de rayos, que se representa en manto de armiño bajo yelmo con corona del Emperador y collar del que pende una cruz laureada de cinco pares de puntas, con un águila en su interior, distintivo de la Legión de Honor, tras él aparecen cruzados los cetros imperiales.

9 El Depósito de la Guerra nace en el año 1810 como una dependencia del Cuerpo del Estado Mayor, para recopilar y conservar documentación relativa a campañas y actuaciones militares, en general. En el año 1847 se establece el Reglamento del Depósito, que se divide en dos secciones: Sección de Historia y Estadística Militar del Depósito y Sección Topográfica y Militar del Depósito. De la primera dependería el Archivo Histórico del Depósito, creado en 1873. Adscrito a partir del año 1904 al Estado Mayor del Ejército, fue suprimido por Decreto de 28 de julio de 1931 . Sus competencias fueron asumidas, a partir del año 1939, por el Servicio Histórico Militar.

${ }^{10}$ El Ministerio de la Guerra (o de Guerra) fue un departamento gubernamental encargado de los asuntos militares de tierra que estuvo vigente en España entre 1851 y 1939. Esta denominación terminó al finalizar la Guerra Civil Española, cuando Franco, en el verano de 1939 creó los Ministerios del Ejército, Aire y Marina.

${ }^{11}$ Es el escudo real de España bajo el reinado de Carlo IV. Es el Escudo Grande anterior a Carlos III con Toisón y Cruz del Espíritu Santo.

${ }^{12}$ Ligero moaré de Lyón.
}

\section{BIBLIOGRAFÍA}

AKAR, M. Le décor néo-classique des reliures françaises au temps du Directoire, du Consulat et de l'Empire. En Ars \& Metiers du Livre, 2015, n ${ }^{\mathrm{o}} 309$, p. 8.

BLAS BENITO, J. Pascual Carsí y Vidal: encuadernador de Carlos IV y de su Imprenta Real. En Encuadernación de Arte, $1998, \mathrm{n}^{\circ} 11$, p. 33-46.

CARPALLO BAUTISTA, A. Análisis Documental de la encuadernación española: repertorio bibliográfico, tesauro, ficha descriptiva. Madrid, AFEDA, 2002.

— Encuadernaciones del siglo XIX en la Biblioteca Histórica de Madrid. Madrid: Ollero y Ramos, 2015.

L Las encuadernaciones del siglo XVIII de la Catedral de Toledo. Madrid: Ollero y Ramos, 2012.

CARRIÓN GÚTIEZ, M. La encuadernación española en los siglos XIX y XX. En Historia ilustrada del libro español: la edición moderna. Madrid: Fundación Germán Sánchez Ruipérez: Pirámide, 1996, p. 491-539.

CULOT, P. Relieurs et reliures décorées en France aux époques Directoire et Empire. Bruxelles: Bibliotheca Wittockiana, 2000.

DEVEAUX, Y. Les frères Bozerian. En Ars \& Metiers du Livre, 2014, nº 305, p. 84-85.

Enciclopedia de la encuadernación. Madrid: Ollero y Ramos, 1998.

LÓPEZ SERRANO, M. Le décor "de cortina" dans la reliure espagnole de style empire. En Bulletin du bibliophile, $1978, \mathrm{n}^{\mathrm{o}} 1$, p. 22-43.

— Curiosidades de la encuadernación española: el encuadernador Gabriel Gómez 1751?-1818. En Coleccionismo, 1945, año XXI, no 198, p. 68-71.

— La encuadernación madrileña en la época de Carlos IV. En Archivo Español de Arte, 1950, n 90, p. $115-131$.

Encuadernaciones de cortina: originalidades del libro español. En Reales Sitios, 1967, año IV, no 11, p. 22-31.

- El encuadernador Gabriel Gómez Martín. En Revista de Bibliografía Nacional, 1945, T. VI, p. 51-72.

Gabriel de Sancha: editor, impresor y encuadernador madrileño (1746-1820). Madrid: Ayuntamiento: Instituto de Estudios Madrileños, 1975.

—_ Libros encuadernadores de cámara. I. Antonio Suárez. En Arte Español, 1942, T. XIV, p. 7-14.

Libros encuadernadores de cámara. II. Santiago Martín. En Arte Español, 1943, T. XIV, p. 14-28. 